\title{
Contexto Geoambiental da Serra do Juá-Conceição, Região Metropolitana de Fortaleza, Ceará
}

\author{
Geoenvironmental context Juá-Conceição Mountain, The Metropolitan Region of Fortaleza, \\ Ceará State
}

Ribeiro, L.E.; Bastos, F. H.

lucasemersonce@hotmail.com

\begin{abstract}
Resumo
A Serra do Juá-Conceição está localizada no município de Caucaia - Ceará, sendo caracterizada como um dos maciços residuais úmidos da Região Metropolitana de Fortaleza, apresentando uma extensão aproximada de 40 $\mathrm{km}^{2}$, com altitudes médias entre 300 e $500 \mathrm{~m}$. É compreendida em terrenos do embasamento cristalino, destacando o Complexo Gnáissico-Migmatítico. Três subsistemas naturais podem ser destacados na área do maciço e entorno vertentes úmidas pré-litorâneas, vertentes secas e subúmidas e as cristas residuais e inselbergs. A mata plúvio-nebular é identificada das áreas com grandes altitudes e exposições aos ventos úmidos, com a presença de associações entre Argissolos vermelho-amarelos e Neossolos Litólitos, estes últimos encontrados em setores mais inferiores, predominando a vegetação de mata seca. Definida pelo padrão dendrítico, a drenagem possui elevado poder de entalhe, com litologias não favoráveis ao processo de infiltração. O presente trabalho pretende abordar a caracterização geoambiental da serra em destaque visando a contribuição para a elaboração de estratégias relacionadas ao planejamento ambiental, tendo como metodologia o estudo integrado das paisagens a partir dos Geossistemas (BERTRAND, 1971), bem como pela concepção da Ecodinâmica (TRICART, 1977), além das contribuições de Souza (2014), Medeiros (2014) e Saraiva Júnior (2009) na subdivisão dos sistemas ambientais presentes no município de Caucaia.
\end{abstract}

Palavras-chave: Análise Ambiental, Maciço Sub-úmido. Serra do Juá-Conceição.

\begin{abstract}
The Juá-Conceição Mountain is located in Caucaia, Ceará, characterized as one of the residual damp massif of the Metropolitan Region of Fortaleza, showing an approximate extension of $40 \mathrm{~km}^{2}$, with altitudes between $300-500 \mathrm{~m}$. Is compried in the grounds of the crystalline basement, highlighting the complex GnáissicoMigmatítico. Three natural sub-systems can be highlighted in the area of the massif: wet strands, dry strands and sub-wet and the residual ridges and monadnocks. The vegetation-nebular is characteristic of the lower areas with high altitudes and exposures to the moist winds, with the presence of associations between red-yellow Argissolos and Neossolos Litólitos, the latter found in lower sectors, mainly of caatinga vegetation. Defined by the dendritic pattern, has a high drainage slot power, with lithologies not favorable to infiltration process. The present work intends to address the geoenvironmental characterization of mountain highlighted aiming at contribution to the elaboration of strategies related to environmental planning, with methodology the integrated study of the landscapes from the Geossistemas (BERTRAND, 1971), as well for the design of "'Ecodinâmica", (TRICART, 1977), in addition to the contributions of Souza (2014), Medeiros (2014) and Silveira Junior (2009) in the subdivision of the environmental systems present in the Caucaia's City.
\end{abstract}

Keywords: Environmental Analysis. Sub-humid Massif. Juá-Conceição Mountain.

\section{INTRODUÇÃO}

Os relevos serranos dispõem-se, historicamente, como áreas de grande valor ambiental, paisagístico e social. Levando em consideração a abundância de seus recursos naturais atrelados a diversidade biológica, os espaços dos mesmos são cada vez mais requisitados tanto para a utilização comercial de seus bens nativos como para atividades econômicas ligadas ao turismo e lazer, sendo

\footnotetext{
${ }^{1}$ Lucas Emerson Uchôa Ribeiro, Laboratório de Estudos Morfoestruturais e Pedológicos, Universidade Estadual do Ceará, Fortaleza-CE, Brasil. 
potencialmente adotados também para levantamentos científicos. Por trás disso, possuem diversos aspectos culturais associados aos seus primeiros tipos de ocupações humanas.

O capítulo 13 da Agenda 21, programa resultante do evento intitulado Rio 92, disserta sobre o desenvolvimento sustentável dos relevos montanhosos. Segundo o mesmo documento, tais feições geomorfológicas são extremamente vulneráveis ao desequilíbrio ecológico, que seria passível de ser originado tanto naturalmente como de forma antrópica, sendo as áreas mais sensíveis a qualquer mudança climática ocorrida em diferenciadas escalas de trabalho. Associando os eventos relacionados à evolução das encostas, juntamente às principais atividades humanas realizadas em tais áreas como agricultura, extração mineral, construções urbanas e etc., determinados processos como movimentos gravitacionais de massa, erosão e degradação ambiental ocorrem com maior frequência. Ao mesmo tempo que são definidos como parte da dinâmica natural dos ambientes, populações assentadas em áreas inadequadas à ocupação são afetadas em diferentes proporções pelos mesmos, tendo por muitas vezes consequências severas irreversíveis.

No Nordeste brasileiro, determinadas formas de relevo se destacam em meio ao grande domínio da Depressão Sertaneja, por muitas vezes com características singulares no contexto semiárido regional. Os maciços cristalinos, segundo Brandão (2014), caracterizam-se por feições residuais com grandes dimensões, atingindo cotas elevadas (entre 500 e 1000m), sendo geralmente formados por processos de erosão diferencial e sustentados por rochas mais resistentes ao intemperismo e a erosão em relação ao embasamento cristalino circundante. Constituem-se, em determinadas regiões, brejos de altitude em escalas diferenciadas (SOUZA; OLIVEIRA, 2006), evidenciando áreas sujeitas às influências de mesoclimas de altitude, em especial nas vertentes a barlavento, destacando-se o intemperismo químico e a geração de solos mais profundos com o revestimento de coberturas de Mata Atlântica subperenifólia.

O Complexo Juá-Conceição-Camará é abordado em vários trabalhos como os de Araújo, Silveira e Cruz (2011), Carvalho et al., (2011), Medeiros (2014), Saraiva Júnior (2009) e etc. Levantamos, aqui, somente a análise das áreas em que ocorrem resquícios de enclaves úmidos/subúmidos, para a melhor compreensão dos diferentes tipos de usos que ocorrem nas vertentes úmidas e secas no mesmo relevo em destaque (Serra do Juá-Conceição).

A área escolhida para a discussão do presente trabalho (Mapa 01) está localizada no município de Caucaia - Ceará, demonstrando uma extensão aproximada de $40 \mathrm{~km}^{2}$, com altitudes médias entre 300 e 500m. Apresenta, se comparada a outros maciços residuais do estado do Ceará, altitudes modestas e, juntamente com as Serras de Maranguape e Aratanha, destacam-se como os grandes relevos serranos da Região Metropolitana de Fortaleza. 
O histórico de ocupação da presente serra remete a raízes Quilombolas antigas do século XVIII. Simultaneamente ao aumento de quase $30 \%$ da população na última década do município de Caucaia (IBGE, 2010), diversas famílias abandonaram a localidade em busca de melhores condições de vida, deslocando-se para áreas mais centrais. Atrelado a isso, políticas públicas do município direcionadas à serra não abrangem a totalidade das comunidades provenientes, e muitas vezes mostram-se ineficientes.

A discussão aqui evidenciada tem como objetivo principal expressar as características geoambientais da presente área de estudo, compreendendo os diversificados componentes naturais como relevo, solo, vegetação, clima, recursos hídricos e etc, contribuindo para o conhecimento de uma forma mais integrativa dos elementos naturais da Serra em destaque, atrelado à maneira como os mesmos são utilizados através de práticas antrópicas. Justifica-se, então, de suma relevância para a discussão da ocupação quilombola da Serra concomitante às atividades humanas decorrentes, visto a falta de estudos nesse mesmo viés. Pretende-se, com a caracterização geoambiental proposta, contribuir para a elaboração de estratégias relacionadas ao planejamento ambiental, visando uma maior eficiência da gestão pública na área em evidência.

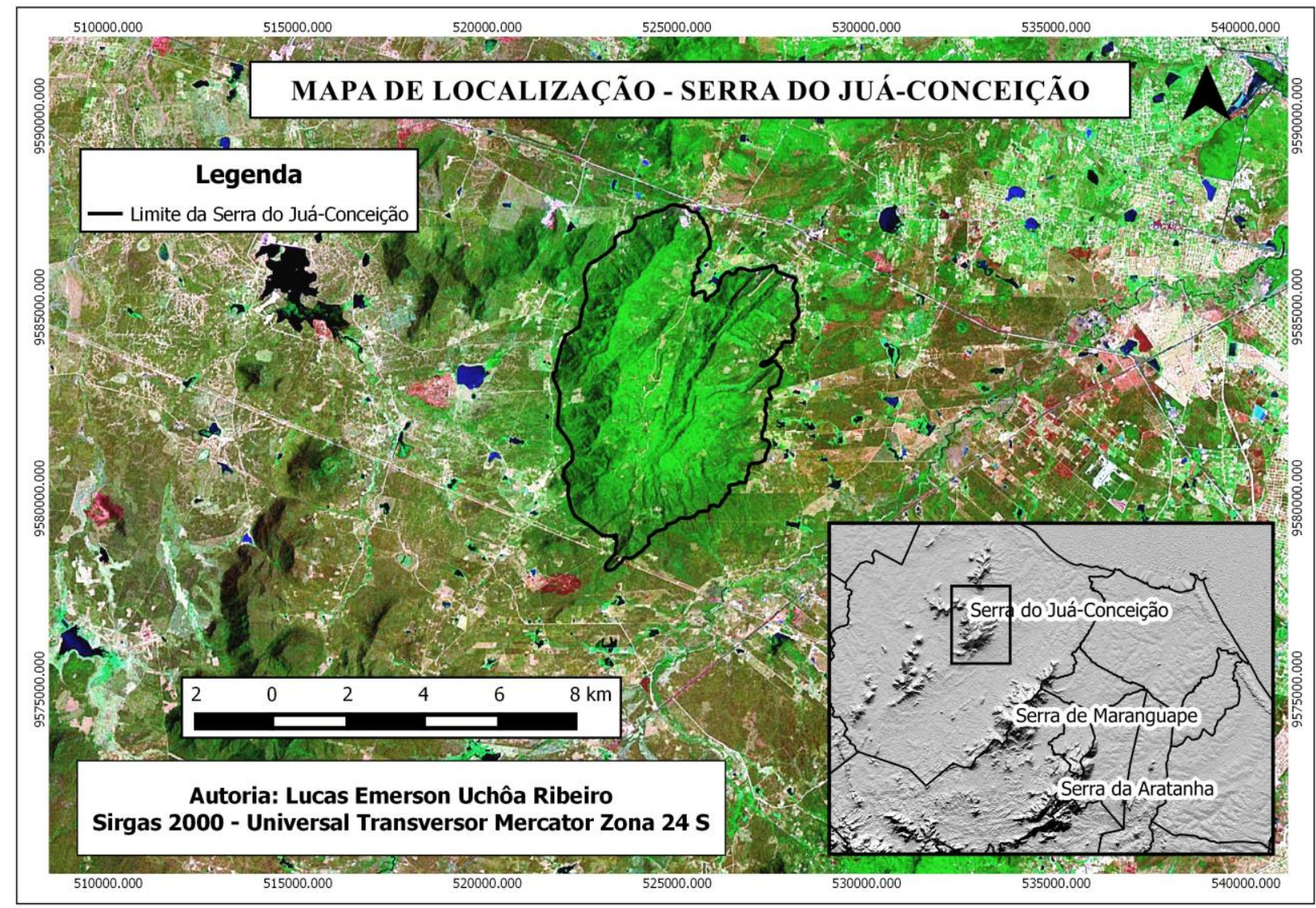

Mapa 01. Localização da Serra do Juá-Conceição. Fonte: elaborado pelo autor. 


\section{METODOLOGIA}

Elaborara-se, como processos metodológicos do presente debate, quatro etapas fundamentais: levantamento bibliográfico, processos cartográficos, trabalho de campo e compreensão dos dados recolhidos.

Destaca-se, na primeira etapa, que a análise geoambiental é uma ferramenta imprescindível para a compreensão das diversas singularidades da natureza. Idealizar a conexão entre sociedade e fenômenos naturais a partir dos Geossistemas (SOTCHAVA, 1962) é associar fenômenos topográficos, biogeográficos, pedológicos, geomorfológicos, hidrológicos e climáticos que, incorporando-se com a ação das atividades antrópicas, compõem uma paisagem integrada, onde o espaço será assimilado como um sistema ambiental, físico e socioeconômico (CHRISTOFOLETTI, 1999). Assim, para a presente discussão, adota-se o método geossistêmico proposto por Bertrand (1971), que define a Geomorfologia como a ciência de caráter delimitativo das unidades de paisagem nos geossistemas, onde a análise geomorfológica deve, incontestavelmente, inserir a compreensão das relações processuais pretéritas e atuais, que são significativas na compreensão racional da forma de apropriação do relevo (CASSETI, 1994).

Compreendendo uma escala geográfica local e regional destacam-se, principalmente, referências como Brandão (2014) e Souza (1988) como suporte a compreensão da compartimentação das unidades geomorfológicas do Estado do Ceará, Oliveira e Souza (2006) no debate dos enclaves úmidos e subúmidos no contexto semiárido nordestino, e Medeiros (2014) e Saraiva Júnior (2009) como base para os levantamentos ambientais no município de Caucaia. Salienta-se, ademais, a consulta a materiais em órgãos públicos como a Companhia de Pesquisa de Recursos Minerais (CPRM), Instituto Brasileiro de Geografia e Estatística (IBGE) e Instituto de Pesquisa e Estratégia Econômica do Ceará (IPECE).

$\mathrm{Na}$ segunda etapa, as técnicas de geoprocessamento foram essenciais para a confecção do mapa de localização. O mesmo teve como base cartográfica a imagem Geocover Landsat obtida através da NASA - National Aeronautics and Space Administration - que recobre a área de estudo, juntamente a cenas SRTM adquiridas no INPE - Instituto Nacional de Pesquisas Espaciais - para o levantamento dos parâmetros altimétricos com a delimitação da serra em destaque na cota de 80m, sendo utilizada a carta O3S39_. Os shapes para a divisão dos municípios do Estado do Ceará foram obtidos através do IBGE - Instituto Brasileiro de Geografia e Estatística, e o programa utilizado foi o Quantum Gis 2.10.1, software livre desenvolvido pelo OSGeo - Open Source Geospatial Foundation. 
É ressaltada, na terceira etapa, a análise de campo com finalidade exploratória que, a partir dos dados adquiridos na primeira fase, pôde-se contestar no exame empírico como tais informações espacializavam-se na presente área de estudo. Na quarta e última etapa, a interpretação dos dados colhidos foi de extrema importância para os resultados que estão explicitados no fim desta discussão.

\section{RESULTADOS E DISCUSSÃO}

A Serra do Juá-Conceição é caracterizada por um maciço residual de litologias do complexo Gnáissico-Migmatítico inseridos no Domínio Ceará Central, localizado no Setor Setentrional da Província Borborema, com a predominância de biotita-gnaisses e ortoderivados, além de relativas incidências de migmatitos e granitos, verificando-se recobertos em algumas incisões pelo Grupo Barreiras e ocupando grande parte do município de Caucaia (MEDEIROS, 2014).

Tal localidade está inserida na Bacia Hidrográfica Metropolitana, e a presente serra contempla as sub-bacias dos Rios Cauhipe, Ceará e Juá. Para Saraiva Júnior (2009), os maciços residuais constituem importantes divisores de águas, onde o padrão dendrítico indagado na base das vertentes de tais relevos alcança um caráter de drenagem paralela nas proximidades do litoral, influenciado tanto pela declividade como pela permoporosidade dos pacotes rochosos. Possui ainda um saliente poder de entalhe, auxiliando na dissecação do relevo em feições de cristas e de colinas. Devido à resistência litológica, a infiltração é coibida exceto em áreas fraturadas, verificando-se, assim, baixos potenciais de águas subterrâneas.

Souza (2000) discute que os maciços residuais se constituem em grandes áreas elevadas, detendo relevos fortemente dissecados em formas de topo convexos e aguçados, com interflúvios dotados de declives mais suaves e vales medianos e fortemente profundos. A serra da presente discussão apresenta altitudes médias entre 300 e $500 \mathrm{~m}$, com picos altimétricos de até $620 \mathrm{~m}$. É escavada pelo riacho Juá, abaixo de cristas mantidas acima dos 400m (SARAIVA JÚNIOR, 2009)

Em caráter pedológico, a partir de dados recolhidos tanto no Plano Diretor de Desenvolvimento Urbano de Caucaia (PDDU, 2011) como na Base cartográfica do Pólo Ceará Costa do Sol (IPECE, 2008), tem-se a predominância da Associação de Neossolos Litólitos e Argissolos Vermelho-Amarelos. Os primeiros prevalecem em áreas onde a dissecação é mais nítida, em encostas de relevos que variam tanto de suavemente ondulados até montanhosos e escarpados, com ocorrências também em áreas planas. Apresentam-se como solos rasos a muito rasos, não hidromórficos, pouco desenvolvidos, bem drenados e com constante ocorrência de afloramentos rochosos. Possuem textura arenosa até siltosa, sendo moderadamente ácidos a praticamente neutros, com a vegetação de caatinga ocorrendo de forma preponderante. Frequentemente ocorrem 
associados à Argissolos Vermelho-Amarelos. Estes últimos identificam-se com profundidades muito a moderadamente profundas, com textura média argilosa, bem drenados e de acidez elevada (BRANDÃO, 2014; SOUZA, 2000, 2009; MEDEIROS 2014).

De acordo com Souza (2000), determinados mesoclimas que se estabelecem dentro do domínio climático do semiárido são capazes de manter formações florestais úmidas e subúmidas com matas de caráter preponderantemente perenifólio, ocorrendo também as comunidades subperenefólias. Assim, a ação combinada dos fatores de altitude entre "600 a 1.200 metros" (BÉTARD; PEULVAST; SALES, 2007) e temperaturas amenas, possui um papel fundamental para a existência desses ambientes.

Caracterizada como uma área para a passível ocorrência de brejos de altitude, a serra abriga diversos complexos vegetacionais. A Mata Plúvio-Nebular ocorre nos setores mais elevados da Serra do Juá-Conceição, a partir da cota dos 600 metros de altitude (SARAIVA JÚNIOR, 2009), com a predominante umidade atmosférica alta, constantes chuvas orográficas e solos mais profundos, se constituindo como uma unidade vegetacional de porte arbóreo, além da existência de remanescentes da Mata Atlântica. A Mata Seca, outro presente complexo serrano, aparece em níveis inferiores concomitantes a vertentes de sotavento, tendo como espécies características as de porte arbóreo, intermediários entre a Mata Plúvio-Nebular e a Caatinga (BRANDÃO, 2014; SOUZA 2000).

A ocupação e o uso da terra na presente área de estudo se dão através de diversas práticas. A atividade mineradora pode ser constatada de maneira decorrente por conta da oferta natural de rochas graníticas, migmatíticas e vulcânicas, onde diversas empresas fazem a extração das mesmas. A partir do momento em que a paisagem é modificada, determinados impactos manifestam-se negativamente tanto para a mesma como como as comunidades mais próximas. Com a remoção da vegetação para a extração das litologias, o solo exposto tende a contaminar-se por conta dos produtos químicos utilizados nas mesmas atividades, e a partir do momento em que as empresas não reparam o solo, os processos erosivos são agravados.

A agricultura de subsistência também é uma atividade característica presente no maciço. Observa-se que, a partir da preparação do terreno através de queimadas para o cultivo de outras culturas (substituição da cobertura vegetal), principalmente nos setores mais úmidos, processos erosivos e movimentos gravitacionais de massa são destacados especialmente em períodos chuvosos. Destaca-se aqui o cultivo de bananeiras principalmente nas superfícies de cimeira da presente serra, bem como do feijão, milho e mandioca na vertente oriental da Conceição e ocidental do Juá. 
A partir do século XVIII, diversos escravos fugidos começaram a ocupar a presente serra, integrando famílias e formando as comunidades quilombolas da Serra do Juá e da Serra da Conceição. O patrimônio histórico-cultural revela que, com a criação de moradias de maneira desordenada e com a libertação dos escravos sem a inserção imediata como indivíduos na sociedade, as condições de pobreza sempre foram presentes nos moradores, e as residências foram construídas em condições precárias.

Com o passar dos anos, algumas famílias se deslocaram para áreas mais centrais do município de Caucaia em busca de melhores condições de vida, e a serra começa a ganhar visibilidade de órgãos municipais, estaduais e federais. Porém, os serviços atualmente se mostram ainda ineficazes, como a energia elétrica que não chega de maneira produtiva a todas as residências, saneamento básico precário, falta de transporte da serra para outras áreas devido ao fator altimétrico limitante, e carência de incentivos a agricultura familiar. Este último serviço, juntamente à ineficiência de saneamento básico de qualidade, revela grandes possíveis riscos ambientais, levando em consideração processos agrícolas feitos muitas vezes de maneira predatória, além do escoamento superficial de resíduos contaminados, transferindo, por exemplo, os mesmos para determinados recursos hídricos próximos, com o eventual desencadeamento de processos erosivos e gravitacionais, que podem atingir as moradias que estiverem em áreas circundantes.

\section{CONSIDERAÇÕES FINAIS}

Face ao exposto na presente discussão, um grande desafio a todos nós é proposto: como utilizar, através de práticas sustentáveis, os recursos naturais da serra em destaque sem impactarmos negativamente a dinâmica natural e cultural? E caso isso não ocorra, de que maneiras a resiliência ambiental responderá a tais consequências, e quais métodos poderão ser utilizados para recuperar os danos causados?

Não cabe aqui responder a tais questionamentos através de soluções concretas que envolvem setores da sociedade bem mais complexos para serem elaboradas na presente escala de trabalho. Pode-se, no entanto, com o estudo apresentado focado nas características geoambientais da Serra do Juá-Conceição, colaborar com estratégias de planejamento ambiental, a partir da análise integrada feita anteriormente. É verídico que a natureza, em seu completo conjunto paisagístico, necessita de uma compreensão holística entre todos os seus elementos condicionantes, para que as atividades humanas sejam feitas de maneira adequada.

É importante que os órgãos ambientais, em diferentes esferas, analisem a herança histórica deixada pelos antigos moradores da serra antes de quaisquer modificações em bases legais. Reconhecidas pela Fundação Palmares, as comunidades Quilombolas provenientes da Serra do Juá- 
Conceição estabelecem-se como as primeiras ocupações da mesma, e sofrem ainda com problemas de titulação das terras e descaso governamental. Necessita-se, assim, de uma gestão integrativa que possa contemplar as antigas raízes históricas, bem como a apropriação dos setores econômicos através de técnicas sustentáveis.

Ressaltam-se as grandiosas contribuições da Geografia como uma ciência integrativa entre os aspectos físicos e sociais constituintes das paisagens, bem como da Geomorfologia pela associação entre a compreensão da origem e evolução das formas de relevo, atrelados a ambientes atuais e antigos. A partir do momento em que as relações de uso da terra entram em conflito com as formas estruturais naturais, a abordagem geossistêmica insere-se como caráter prioritário para o uso de forma satisfatória dos recursos ambientais.

\section{REFERÊNCIAS}

ALBUQUERQUE, E.M.L; LIMA, K.A; MEDEIROS, C.N; SOUSA, F.J; SOUZA, M.J.N. PERFIL GEOSSOCIOECONÔMICO: Um olhar para as Macrorregiões de Planejamento do Estado do Ceará. Fortaleza: IPECE, 2014. 174 p.

ARAÚJO, T.S; CRUZ, M.L.B; SILVEIRA, L.M.M. Determinação da vulnerabilidade ambiental, através das técnicas de sensoriamento remoto, na Serra Juá-Conceição-Camará, Caucaia/CE. Anais XV Simpósio Brasileiro de Sensoriamento Remoto - SBSR, 2011. Curitiba: 2011.

BÉTARD, F; PEULVAST, J.P; SALES, V.C. Caracterização morfopedológica de uma serra úmida no semiárido do nordeste brasileiro: o caso do maciço de Baturité-CE. Mercator - Revista de Geografia da UFC. Fortaleza: Universidade Federal do Ceará, 2007.

BERTRAND, G. Paisagem e Geografia Física Global: Esboço Metodológico. Cadernos de Ciência da Terra São Paulo, 1971, n.13. Curitiba: 2004.

BRANDÃO, R.L. Geodiversidade do Estado do Ceará. Fortaleza: CPRM, 2014, 214 p.

BRASIL, Ministério do Meio Ambiente. Agenda 21. Disponível em: http://www.mma.gov.br/responsabilidade-socioambiental/agenda-21/agenda-21-global. Acesso em: 24 de julho de 2016.

CARVALHO, G.A; CRUZ, M.L.B; LIMA, D.B; SILVEIRA, L.M.M. Uso de sensoriamento remoto no estudo do brejo de altitude da Serra Juá-Conceição- Camará, Caucaia/CE. Anais XV Simpósio Brasileiro de Sensoriamento Remoto - SBSR, 2011. Curitiba: 2011.

CASSETI, V. Ambiente e Apropriação do Relevo. São Paulo: Editora Contexto, 1994. 147p.

CHRISTOFOLETTI, A. Geomorfologia. 2a edição. São Paulo: Edgard Blücher, 1999. 149p.

IBGE - Instituto Brasileiro de Geografia e Estatística. Censo Demográfico de 2010. 2010. Disponível em: www.sidra.ibge.gov.br. Acesso em: 24 de julho de 2016. 
IPECE - Instituto de Pesquisa e Estratégia Econômica do Ceará. Base cartográfica do Pólo Ceará Costa do Sol. Nota técnica $\mathrm{n}^{\mathrm{o}}$ 35. 2008. Disponível em: <http://www.ipece.ce.gov.br/publicacoes/notas_tecnicas/NT-35.pdf>. Acesso em: 12 de julho de 2016.

MEDEIROS, C.N. Vulnerabilidade Socioambiental do Município de Caucaia (CE): Subsídios ao Ordenamento Territorial. Tese de doutorado apresentada ao Programa de Pós-Graduação em Geografia da Universidade Estadual do Ceará, 2014, 267 p.

OLIVEIRA, V.P.V; SOUZA, M.J.N. Os enclaves úmidos e sub-úmidos do semiárido do nordeste brasileiro. Mercator - Revista de Geografia da UFC, 2006, n. 9, v.5. Fortaleza: 2006.

PLANO DIRETOR DE DESENVOLVIMENTO URBANO - PPDU. Lei ambiental e de Organização Territorial. 2001. Disponível em: <http://www.caucaia.ce.gov.br/sessoes/cidadao/pddu.php> Acesso em: 22 de julho de 2016.

SARAIVA JÚNIOR, J.C. Geomorfologia dos Maciços Costeiros de Caucaia. Dissertação de mestrado apresentada ao Programa de Pós-Graduação em Geografia da Universidade Federal do Ceará, 2009. 151 p.

SOTCHAVA, V. B. Définition de quelques notions et termes de Géographie Physique. Dokl. Institute de Géographie de la Sibérie et Extrême Orient, n. 3, 1962. p. 94-117.

SOUZA, G.M. Modelagem Ambiental para a Delimitação de Brejos de Altitude com Estudo de Casos para os Maciços da Aratanha, Maranguape, Juá e Conceição - Estado do Ceará. Dissertação de mestrado apresentado ao Programa de Pós-Graduação em Geografia da Universidade Estadual do Ceará, 2014. 139 p.

SOUZA, M.J.N. Contribuição ao estudo das unidades morfo-estruturais do estado do Ceará. Revista de Geologia, v. 1, n. 1, 1988, p. 73-91.

SOUZA, M. J. N. In: LIMA, L. C; SOUZA, M. J. N; MORAES, J. O. Compartimentação territorial e gestão regional do Ceará. Fortaleza: FUNECE. 2000.

SOUZA, M. J. N; NETO, J. M; SANTOS, J. O; GONDIM, M. S. Diagnóstico Geoambiental do Município de Fortaleza: subsídios ao macrozoneamento ambiental e à revisão do plano diretor participativo - PDPFor. Fortaleza: Prefeitura Municipal de Fortaleza, 2009, 172 p.

TRICART, J. Ecodinâmica. Rio de Janeiro: FIBGE, Diretoria Técnica, 1977. 91p.

Recebido em: 14/08/2016

Aceito para publicação em: 01/10/2016 